\title{
The influence of decompressive craniectomy on the development of hydrocephalus: a review
}

\author{
A influência da craniotomia descompressiva no desenvolvimento de hidrocefalia: uma revisão \\ Jun Ding, Yan Guo, Hengli Tian
}

\begin{abstract}
Decompressive craniectomy (DC) is widely used to treat intracranial hypertension following traumatic brain injury (TBI) or cerebral vascular disease. Many studies have discussed complications of this procedure, and hydrocephalus is a common complication of DC. To further evaluate the relationship between DC and hydrocephalus, a review of the literature was performed. Numerous complications may arise after DC, including contusion or hematoma expansion, epilepsy, herniation of the cortex through a bone defect, CSF leakage through the scalp incision, infection, subdural effusion, hydrocephalus and "syndrome of the trephined". Several hydrocephalus predictors were identified; these included DC, distance from the midline, hygroma, age, injury severity, subarachnoid or intraventricular hemorrhage, delayed time to craniotomy, repeated operation, and duraplasity. However, results differed among studies. The impact of DC on hydrocephalus remains controversial.
\end{abstract}

Keywords: traumatic brain injury, hydrocephalus, decompressive craniectomy.

\section{RESUMO}

A craniectomia descompressiva (CD) é amplamente utilizada para tratar a hipertensão intracraniana após trauma craniencefálico (TC) ou doença cerebrovascular. Vários estudos discutem as complicações deste procedimento, sendo a hidrocefalia uma das complicações mais frequentes. Fizemos uma revisão da literatura para avaliar a relação entre a CD e a hidrocefalia. Podem ocorrer numerosas complicações após a CD, incluindo aumento de volume por contusão ou hematoma, epilepsia e herniação do cortex cerebral através do acesso ósseo. Fístulas liquóricas através a incisão no couro cabeludo, infecções, hematomas subdurais, hidrocefalia e a "síndrome pós-trepanação". Foram identificados vários fatores preditivos de hidrocefalia: a distância da CD em relação à linha média, a ocorrência de higroma, a idade, a gravidade da lesão, a hemorragia subaracnóidea ou intraventricular, o tempo decorrido até a craniectomia, as reoperações e o uso de plástica com dura-máter. Entretanto, há divergências entre os autores e o impacto da CD na hidrocefalia continua controvertido.

Palavras-chave: trauma cranencefálico, hidrocefalia, craniectomia descompressiva.

\section{INTRODUCTION}

Traumatic brain injury (TBI) constitutes an important public health issue, and decompressive craniectomy (DC) is a life-saving strategy for patients who suffer from severe $\mathrm{TBI}^{1,2}$, aneurysmal subarachnoid hemorrhage $\left(\mathrm{SAH}^{3,4}\right.$, malignant middle cerebral artery/internal carotid artery territory infarction ${ }^{5,6}$, and severe cerebrovenous and dural sinus thrombosis ${ }^{7,8}$. The complication rates of this procedure are a major determinant of whether DC is superior to medical treatment for patients with intracranial hypertension after TBI or other central nervous system (CNS) diseases. Many of the complications of DC arise from the normal pathophysiological changes that occur in intracranial pressure (ICP), cerebral spinal fluid (CSF) circulation, and cerebral blood flow (CBF) following removal of a large area of the skull.

Hydrocephalus is a common complication after TBI or ischemic stroke, particularly in patients who need DC (Figure). The incidence of hydrocephalus varies from $0-45 \%$, depending on the study $y^{9,10,11,12,13}$. Some authors believe that DC is a risk factor for hydrocephalus ${ }^{14,15}$, whereas others do not ${ }^{9,11,12,16}$. Thus, the relationship between DC and hydrocephalus remains controversial.

Studies investigated the occurrence of hydrocephalus after DC in patients with TBI and ischemic stroke have increased in recent years. However, most of these studies have focused on the incidence of hydrocephalus or 

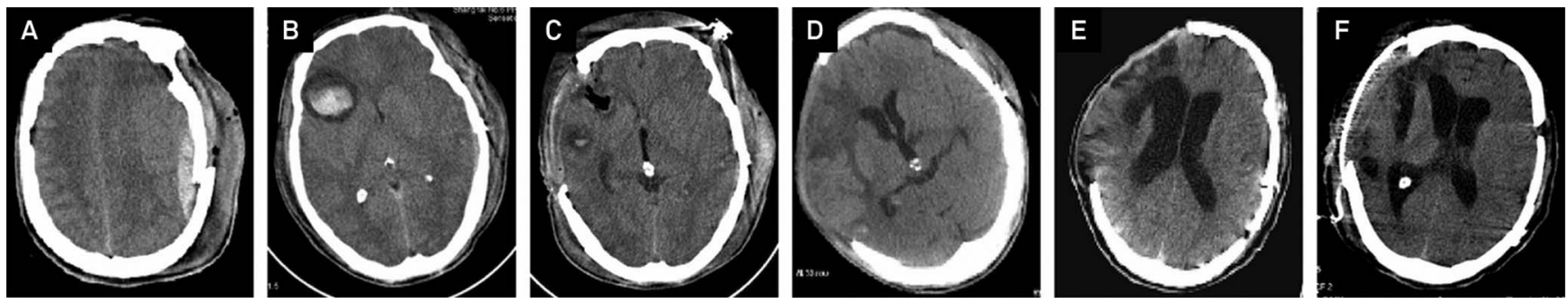

Figure. Patient suffering from an epidural hematoma and cranial fracture (A). A new hematoma appeared after surgery contralateral to the epidural hematoma (B). The patient underwent evacuation of the hematoma and a decompressive craniectomy (C). Ventriculomegaly appeared (D). Hydrocephalus (E). Patient underwent a ventricular-peritoneal shunt and a cranioplasty (F).

complications of DC, only a few used multivariate analyses to analyze the relationship between DC and hydrocephalus.

The purpose of this review was to evaluate the influence of DC on the development of hydrocephalus after TBI or ischemic stroke by performing a literature search and analysis of the available scientific studies.

\section{SEARCH STRATEGY}

An electronic search strategy was designed to identify human TBI or ischemic stroke studies concerning the occurrence of hydrocephalus associated with DC. A review of the literature was performed following a detailed search of PubMed between 2000 and 2012, with the aim of evaluating the impact of DC on hydrocephalus.

\section{Complications following decompressive craniectomy}

Authors have investigated complications after DC in recent years. Complications secondary to DC occur at a rate of almost $50 \%$ and occur in a sequential fashion at specific times after DC. The most frequent complications early after DC are contusion or expansion of a hematoma and a newly appearing subdural or epidural hematoma contralateral to the bone defect (within 3 days), epilepsy (within 3 days), herniation of the cortex through the bone defect (within 5 days) and CSF leakage through the scalp incision (within 7 days); after 7 days, infection and subdural effusion develop between 1 week and 1 month; hydrocephalus and "syndrome of the trephined" occur after 1 month ${ }^{17,18}$.

Among these complications, the most frequent is subdural effusion, but the incidence differs among studies from $11.2-62 \%$. Other complications that often occur after DC are herniation of the cortex through the bone defect (14.6-51\%), seizure (3.4-22\%), hydrocephalus (7.9-14\%), and infection (4.5-15.7\%); others, such as CSF leakage and syndrome of trephined, occur infrequently ${ }^{10,17,18,19,20}$.

In addition to these complications, Ban et al. reported that about $5.6 \%$ of patients suffer from a newly appearing subdural or epidural hematoma contralateral to the bone defect and $12.4 \%$ suffer expansion of the contusion ${ }^{18}$. Additionally, Yang et al. reported a $9.6 \%$ incidence of intracranial hematoma after DC contralateral to the craniectomy defect ${ }^{17}$. These two complications are classified as progressive hemorrhagic injury (PHI) after TBI. In our studies, PHI is defined as an increase in hematoma volume or a new appearance on a repeat computed tomography (CT) $\operatorname{scan}^{21,22}$. DC is a risk factor for progressive epidural hematoma ${ }^{23}$; this may occur because of a reduction or loss of the tamponade effect and may develop early after decompression, but the tamponade effect has not been well documented in clinical reports ${ }^{24}$.

The complications of DC are summarized in Table.

\section{Development of hydrocephalus after DC}

The development of hydrocephalus after DC has been studied in different diseases. However, most have discussed the occurrence of hydrocephalus in patients with CNS diseases who underwent DC, but only a few reported the development of hydrocephalus in total TBI patients, and only a few used multivariate analyses to analyze the relationship between DC and hydrocephalus.

\section{Incidence of hydrocephalus after DC}

The incidence of hydrocephalus after DC has been studied, which was reported to be $0-88.2 \%$. The wide variation is due to differing hydrocephalus evaluation criteria and study inclusion criteria ${ }^{25}$. Some authors consider hydrocephalus as radiographic evidence of ventricular dilatation and/or the presence of an enlarging extra-axial collection of CSF on serial CT imaging; the incidence of hydrocephalus in such studies is high. Waziri et al. reported that patients who underwent DC have a $88.2 \%$ occurrence of hydrocephalus, but only 17 patients were enrolled in that study ${ }^{26}$. Lee et al. reported a $41.2 \%$ incidence of hydrocephalus in patients who suffer from malignant middle cerebral artery infarction and underwent $\mathrm{DC}^{27}$. De Bonis and colleagues found a lower incidence of hydrocephalus after DC (34.5\%) according to more strict criteria: radiographic evidence of progressive ventricular dilatation with an Evan index $>0.3$, associated with narrowed CSF spaces at the convexity on serial CT imaging ${ }^{28}$. Others defined hydrocephalus as progressive ventricular dilatation with trans-ependymal edema, together with (1) the presence of either clinical deterioration 


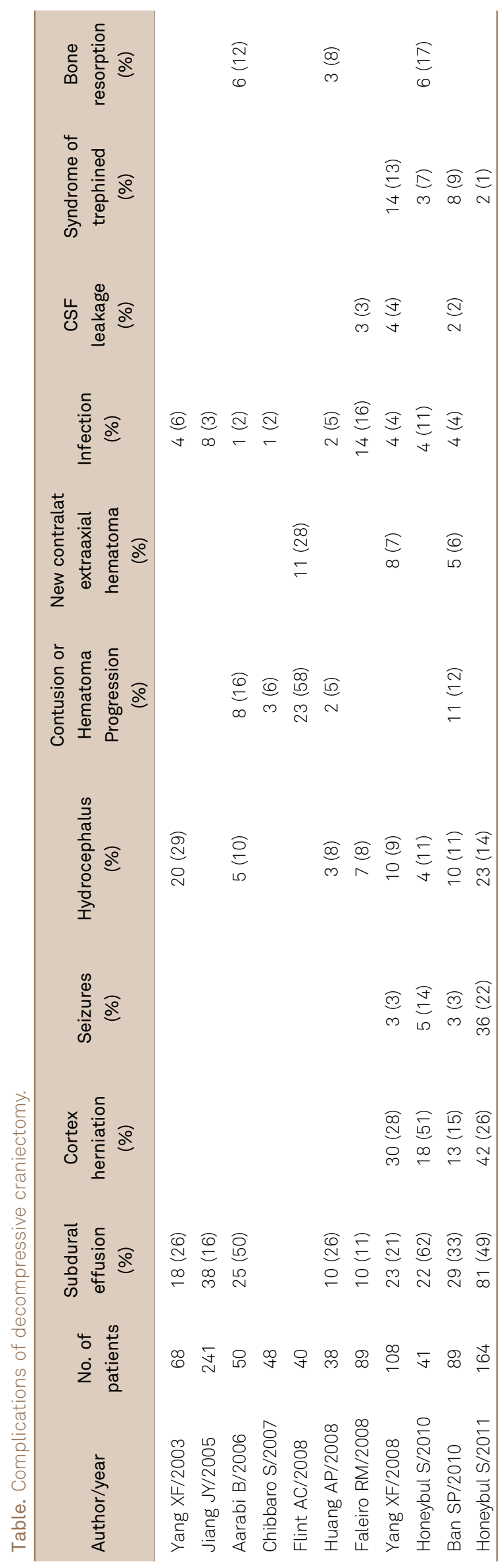

or failure to make neurological progress over time, and (2) some evidence of clinical improvement after insertion of a ventriculo-peritoneal shunt (V-P shunt). The incidence of hydrocephalus in these studies is low $^{9,11,15}$. Rahme et al. enrolled 17 patients in a retrospective study and found that the incidence of hydrocephalus after DC was $0 \%^{9}$. Choi et al. reported a $23.6 \%$ occurrence of hydrocephalus after $\mathrm{DC}^{15}$. However, in another study, this percentage increased to $45 \%{ }^{11}$. This discrepancy may be associated with study inclusion criteria.

Studies focusing on hydrocephalus after DC have reported varying results due to differing inclusion criteria. Tian et al. enrolled all patients with TBI and excluded only a small portion of patients who suffered from spontaneous SAH and penetrating wounds, those who died during the course of analysis, or those who had hydrocephalus before injury. The incidence of hydrocephalus in all patients was $11.96 \%$, and $8.62 \%$ in patients who underwent $\mathrm{DC}^{12}$. Rahme et al. enrolled only patients who suffered from brain infarction, hemorrhagic transformation of brain ischemia, dural sinus thrombosis, or a hemorrhagic cerebrovascular accident. They excluded patients with SAH, intraventricular hemorrhage (IVH), or head trauma, all of which are risk factors for hydrocephalus. As a result, they reported that no hydrocephalus develops after $\mathrm{DC}^{9}$. Other studies enrolled participants who suffered from severe TBI. Kaen et al. found a 27.3\% incidence of hydrocephalus after DC in patients with severe $\mathrm{TBI}^{16}$. Jiao et al. and Honeybul et al. found a $45 \%$ incidence of hydrocephalus in patients with severe $\mathrm{TBI}^{11,14}$.

Thus the incidence of hydrocephalus after DC differs among studies due to dissimilar definitions of hydrocephalus and study inclusion criteria.

\section{Mechanisms of hydrocephalus after DC}

Ventriculomegaly is a common sequela of severe $\mathrm{TBI}^{29,30}$. The most important mechanism is CSF malabsorption or obstruction of CSF flow. Waziri et al. reported that DC may play a "flattening" role in the normally dicrotic CSF pulse wave in patients who undergo DC because of transmission of a pressure pulse out through the cranial defect ${ }^{26}$. Arachnoid granulation function is dependent on the pressure difference between the subarachnoid space and draining venous supply; so, it is possible that disruption of pulsatile intracranial pressure (ICP) dynamics secondary to opening the cranial defect results in decreased CSF outflow and absorption; thus, leading to hydrocephalus. SAH or IVH after TBI may promote the development of hydrocephalus after DC. Blood products may block CSF circulation or absorption via an obstructive mechanism, due to a disturbance in CSF absorption at the arachnoid granulation site ${ }^{31,32,33}$. CSF absorption decreases and accumulation increases, resulting in development of chronic hydrocephalus. Acute hydrocephalus is caused mainly by intraventricular obstruction ${ }^{34}$. 
In addition to the mechanism described above, several authors found that ventriculomegaly can be attributed mainly to an atrophic process secondary to diffuse brain injury. Patients show a progressive increase in ventricular size with no apparent clinical change, and some may benefit from shunting $g^{30,35}$.

\section{What risk factors have been identified for the development of hydrocephalus following DC?}

Risk factors of hydrocephalus following DC in patients who suffered from TBI or cerebral vascular disease were also studied. The factors associated with hydrocephalus are always controversial. Almost all studies were retrospective and only some used multivariate analyses to investigate risk factors associated with hydrocephalus post TBI or other CNS diseases.

DC itself is a risk factor for hydrocephalus in patients who suffer TBI. The effect of the skull and dura on CSF hydrodynamics is important, and a large DC might facilitate ventricular enlargement. In contrast, DC may also reduce intracranial pressure secondary to brain edema and resistance to CSF outflow, which may promote CSF absorption into pachionian granules. Jiao et al. found a significant influence of DC on hydrocephalus after TBI (odds ratio [OR], 4.312; 95\%CI, 1.127-16.503) by a multivariate analysis ${ }^{14}$. The correlation between hydrocephalus and DC appears to be more relevant in the presence of larger craniectomies ${ }^{36}$. Choi et al. reported that the size of DC is an influencing factor for hydrocephalus after TBI. They found that bilateral DC has a higher incidence of hydrocephalus than that of unilateral $\mathrm{DC}^{15}$. However, they did not use multivariate analysis. Additionally, Shi et al. found that bilateral DC is a risk factor for hydrocephalus after TBI via a univariate analysis ${ }^{37}$. However, they did not compare patients with and without DC, so were unable to confirm that DC is an independent risk factor for hydrocephalus.

In some studies, the distance from the midline was independently associated with the development of hydrocephalus. De Bonis et al. reported that the distance from the midline is the only factor associated with hydrocephalus after $\mathrm{TBI}^{28}$. They considered that extracellular fluid is absorbed during the diastolic phase of the cardiac cycle, and that this causes a decrease in brain parenchyma volume and a consequent increase in ventricular volume, which causes hydrocephalus. Anile et al. found that when the skull is removed too close to the midline, the external force compressing the veins mainly during the diastolic phase is reduced, causing an increase in venous outflow and extracellular fluid absorption and a decrease in brain parenchyma volume, which causes ventriculomegaly and hydrocephalus ${ }^{38}$. Takeuchi et al. reported that the distance from the decompressive defect to the midline shows a strong trend for an association with ventriculomegaly after DC in patients who suffered from intracerebral hemorrhage (ICH) besides meningitis, but it was not an impact factor for ventriculomegaly $(\mathrm{p}=0.051$ ). They did not investigate the relationship between DC itself and ventriculomegaly or hydrocephalus ${ }^{39}$.

In contrast, some authors have noted that DC is not an impact factor for hydrocephalus after TBI or cerebral vascular disease. Waziri et al. retrospectively analyzed a cohort of consecutive patients who suffered from cerebral vascular disease and emergent hemicraniectomy for medically refractory elevations in intracranial pressure. They excluded patients with known independent risk factors for the development of hydrocephalus after DC, and no relationship was found between DC and hydrocephalus ${ }^{26}$. Additionally, Rahme et al. found that none of the 17 patients who underwent DC and were enrolled in their study developed clinically significant hydrocephalus requiring diversion of CSF, indicating that DC is not an independent factor for hydrocephalus 9 . Different from these two studies, which focused on patients with cerebral vascular disease, we used multivariate analysis to investigate the risk factors for hydrocephalus after DC in patients with TBI, and found no relationship between DC and hydrocephalus ${ }^{12}$. Hence, the effects of DC on the development of hydrocephalus remain controversial, and it is difficult to explain the nature of the influence.

Age was correlated with the development of hydrocephalus in our previous study ${ }^{12}$. This result was also reported by Jiao et al. ${ }^{14}$. Some authors have reported that the extent of meningeal fibrosis can increase in older patients, which impairs CSF circulation and decreases CSF absorption ${ }^{40}$. Moreover, the wider subarachnoid space in older patients can contain larger volumes of subarachnoid blood after TBI; thus, increasing their risks for developing a CSF circulation disturbance ${ }^{41}$.

Injury severity is another impact factor for hydrocephalus. In a multivariate analysis, Honeybul et al. found that maximum ICP prior to decompression $(\mathrm{p}=0.012)$ and admission Glasgow Coma Score (GCS) ( $\mathrm{p}=0.009)$, which are indicators of injury severity, are significant independent risk factors for development of hydrocephalus after DC, but they found no relationship between the craniectomy margin and hydrocephalus ${ }^{11}$, which differs from a report by De Bonis et $\mathrm{al}^{28}$. Their results suggest that damage to the CSF drainage pathways contributes to the primary brain injury, rather than the craniectomy margin, as a factor responsible for hydrocephalus. Additionally, Shi et al. reported that patients with low GCS tend to develop post-traumatic hydrocephalus (PTH) after $\mathrm{DC}^{37}$. Different from the results described above, our retrospective study found no relationship between admission GCS score and hydrocephalus ${ }^{12}$. A more severe brain injury, including severe cerebral contusion and diffuse axonal injury, can be expected to produce more severe CSF absorption disturbance, favoring ventricular enlargement. 
However, the increasing number of deaths in patients with a low GCS score may reduce the possibility of delayed development of hydrocephalus after head injury ${ }^{42}$.

$\mathrm{SAH}$ and IVH, which are CSF circulation disturbance factors, are also commonly reported to be associated with hydrocephalus. Jiao et al. found a strong relationship between $\mathrm{SAH}$ and hydrocephalus after logistic regression (OR, 43.42; 95\%CI, 7.84-240.65) ${ }^{14}$. Our results show that the distribution of traumatic subarachnoid hemorrhage (tSAH) and thickness of tSAH are risk factors for PTH, with an ORs of $3.61(95 \% \mathrm{CI}, 1.38-9.44, \mathrm{p}<0.01)$ and $4.12(95 \% \mathrm{CI}$ 1.792-9.46, $\mathrm{p}<0.001)$, respectively ${ }^{12}$. Simultaneously, we found that IVH is the strongest impact factor for hydrocephalus after DC with an OR of 6.56 (95\%CI, 2.76-15.63, $\mathrm{p}<0.001)$. Takeuchi et al. studied patients who underwent DC with evacuation of a hematoma for hemispheric hypertensive intracerebral hemorrhage. They found that the presence of IVH was significantly associated with the development of ventriculomegaly $(p<0.05)^{39}$. The distance from the decompressive defect to the midline and the presence of meningitis showed a strong trend for an association with ventriculomegaly. Hydrocephalus occurs in patients with $\mathrm{SAH}$ or IVH mainly via an obstructive mechanism.

Some authors have reported that hygroma (subdural or interhemispheric) is an impact factor for hydrocephalus after DC. Kaen et al. retrospectively studied 73 patients with severe head injury who required $\mathrm{DC}^{16}$. After uni- and multivariate analyses, they concluded that the presence of interhemispheric hygromas was the only independent prognostic factor for the development of post-traumatic hydrocephalus with an OR of $28(\mathrm{p}<0.0001)$. Honeybul and Ho studied almost 200 patients and found that subdural hygroma is the only risk factor for hydrocephalus requiring a V-P shunt, besides injury severity ${ }^{11}$. No other studies focused on the impact of hygroma on hydrocephalus development, and so the relationship between hygroma and hydrocephalus remains to be determined.

Other predictors for hydrocephalus after DC, such as delayed time to craniotomy ${ }^{26}$, repeated operation ${ }^{15}$, and duraplasity $^{37}$, are not common. Thus, the risk factors for hydrocephalus remain controversial.

\section{FINAL REMARKS}

$\mathrm{DC}$ is a life-saving strategy in patients who suffer from TBI or other intracranial diseases. Complications after DC include contusion or hematoma expansion, epilepsy, herniation of the cortex through the bone defect, CSF leakage through the scalp incision, infection, subdural effusion, hydrocephalus and "syndrome of the trephined".

Hydrocephalus is a common sequela in patients who have undergone DC. The incidence of hydrocephalus after DC is $0-88.2 \%$, depending on the inclusion criteria and definitions of hydrocephalus used. Hydrocephalus develops mainly due to CSF malabsorption or obstructed CSF flow.

Risk factors for hydrocephalus after DC, include DC, distance from the midline, hygroma, and others. But, various studies have reported different results. DC may or may not be a risk factor for hydrocephalus, and the physiological mechanism by which hydrocephalus develops after hemicraniectomy remains to be determined. Its impact on hydrocephalus remains controversial and so more prospective, multicenter controlled studies are required.

\section{References}

1. Olivecrona M, Rodling-Wahlström M, Naredi S, Koskinen LO. Effective ICP reduction by decompressive craniectomy in patients with severe traumatic brain injury treated by an ICP-targeted therapy. J Neurotrauma 2007;24:927-935.

2. Morgalla MH, Will BE, Roser F, Tatagiba M. Do long-term results justify decompressive craniectomy after severe traumatic brain injury? J Neurosurg 2008;109:685-690.

3. D’Ambrosio AL, Sughrue ME, Yorgason JG, et al. Decompressive hemicranietomy for poor-grade aneurysmal subarachnoid hemorrhage patients with associated intracerebral hemorrhage: clinical outcome and quality of life assessment. Neurosurgery 2005;56:12-20.

4. Schirmer CM, Hoit DA, Malek AM. Decompressive hemicraniectomy for the treatment of intractable intracranial hypertension after aneurysmal subarachnoid hemorrhage. Stroke 2007;38:987-992.

5. Gupta R, Connolly ES, Mayer S, Elkind MS. Hemicraniectomy for massive middle cerebral artery territory infarction: a systematic review. Stroke 2004;35:539-543.

6. Vahedi K, Hofmeijer J, Juettler E, et al. Early decompressive surgery in malignant infarction of the middle cerebral artery: a pooled analysis of three randomized controlled trials. Lancet Neurol 2007;6:215-222.
Keller E, Pangalu A, Fandino J, Könü D, Yonekawa Y. Decompressive craniectomy in severe cerebral venous and dural sinus thrombosis. Acta Neurochir 2005;94:S177-S183.

8. Coutinho JM, Majoie CB, Coert BA, Stam J. Decompressive hemicraniectomy in cerebral sinus thrombosis: consecutive case series and review of the literature. Stroke 2009;40:2233-2235

9. Rahme R, Weil AG, Sabbagh M, Moumdjian R, Bouthillier A, Bojanowski MW. Decompressive craniectomy is not an independent risk factor for communicating hydrocephalus in patients with increased intracranial pressure. Neurosurgery 2010;67:675-678;

10. Honeybul S. Complications of decompressive craniectomy for head injury. J Clinical Neuroscence 2010;17:430-435.

11. Honeybul S, Ho KM. Incidence and risk factors for post-traumatic hydrocephalus following decompressive craniectomy for intractable intracranial hypertension and evacuation of mass lesions. J Neurotrauma 2012;29:1872-1878.

12. Tian HL, Xu T, Hu J, Cui YH, Chen H, Zhou LF. Risk factors related to hydrocephalus after traumatic subarachnoid hemorrhage. Surg Neurol 2008;69:241-246. 
13. Mazzini L, Campini R, Angelino E, Rognone F, Pastore I, Oliveri G. Posttraumatic hydrocephalus: a clinical, neuroradiologic, and neuropsychologic assessment of long-term outcome. Arch Phys Med Rehabil 2003;84:1637-1641.

14. Jiao QF, Liu Z, Li S, et al. Influencing factors for posttraumatic hydrocephalus in patients suffering from severe traumatic brain injuries. Chin J Traumatol 2007;10:159-162.

15. Choi I, Park HK, Chang JC, Cho SJ, Choi SK, Byun BJ. Clinical factors for the development of posttraumatic hydrocephalus after decompressive craniectomy. J Korean Neurosurg Soc 2008;43:227-231.

16. Kaen A, Jimenez-Roldan L, Alday R, et al. Interhemispheric hygroma after decompressive craniectomy: does it predict posttraumatic hydrocephalus? J Neurosurg 2010;113:1287-1293.

17. Yang XF, Wen L, Shen F, et al. Surgical complications secondary to decompressive craniectomy in patients with a head injury: a series of 108 consecutive cases. Acta Neurochir (Wien) 2008;150:1241-1248.

18. Ban SP, Son YJ, Yang HJ, Chung YS, Lee SH, Han DH. Analysis of complications following decompressive craniectomy for traumatic brain injury. J Korean Neurosurg Soc 2010;48:244-250.

19. Faleiro RM, Faleiro LC, Caetano E, et al. Decompressive craniotomy: prognostic factors and complications in 89 patients. Arq Neuropsiquiatr 2008;66:369-373.

20. Honeybul S, Ho KM. Long-term complications of decompressive craniectomy for head injury. J Neurotrauma 2011;28:929-935.

21. Ding J, Yuan F, Guo Y, et al. A prospective clinical study of routine repeat computed tomography (CT) after traumatic brain injury (TBI). Brain Inj 2012;26:1211-1216.

22. Tian HL, Chen H, Wu BS, et al. D-dimer as a predictor of progressive hemorrhagic injury in patients with traumatic brain injury: analysis of 194 cases. Neurosurg Rev 2010;33:359-365.

23. Chen H, Guo Y, Chen SW, et al. Progressive epidural hematoma in patients with head trauma: incidence, outcome, and risk factors. Emerg Med Internat 2012;2012:134905.

24. Flint AC, Manley GT, Gean AD, Hemphill JC 3rd, Rosenthal G. Postoperative expansion of hemorrhagic contusions after unilateral decompressive hemicraniectomy in severe traumatic brain injury. J Neurotrauma 2008;25:503-512.

25. Guyot LL, Michael DB. Post-traumatic hydrocephalus. Neurol Res 2000;22:25-28.

26. Waziri A, Fusco D, Mayer SA, McKhann GM 2nd, Connolly ES Jr. Postoperative hydrocephalus in patients undergoing decompressive hemicraniectomy for ischemic or hemorrhagic stroke. Neurosurgery 2007;61:489-493.

27. Lee $\mathrm{MH}$, Yang JT, Weng $\mathrm{HH}$, et al. Hydrocephalus following decompressive craniectomy for malignant middle cerebral artery infarction. Clin Neurol Neurosurg 2012;114:555-559.
28. De Bonis P, Pompucci A, Mangiola A, Rigante L, Anile C. Posttraumatic hydrocephalus after decompressive craniectomy: an underestimated risk factor. J Neurotrauma 2010;27:1965-1970.

29. Licata C, Cristofori L, Gambin R, Vivenza C, Turazzi S. Post-traumatic hydrocephalus. J Neurosurg Sci 2001;45:141-149.

30. Poca MA, Sahuquillo J, Mataro' M, Benejam B, Arikan F, Ba'guena M. Ventricular enlargement after mod- erate or severe head injury: a frequent and neglected problem. J Neurotrauma 2005;22:1303-1310.

31. Black PL, Tzouras A, Foley L. Cerebrospinal fluid dynamics and hydrocephalus after experimental subarachnoid hemorrhage. Neurosurgery 1985;17:57-62.

32. Blasberg R, Johnson D, Fenstermacher J. Absorption resistance of cerebrospinal fluid after subarachnoid hemorrhage in the monkey: effects of heparin. Neurosurgery 1981;9:686-691.

33. Hasan D, Herve L, Tanghe J. Distribution of cisternal blood in patients with acute hydrocephalus after subarachnoid hemorrhage. Ann Neurol 1992;31:374-378.

34. Symss NP, Oi S. Theories of cerebrospinal fluid dynamics and hydrocephalus: historical trend. J Neurosurg Pediatr 2013;11:170-177.

35. Marmarou A, Foda MA, Bandoh K, Yoshihara M, et al. Posttraumatic ventriculomegaly: hydrocephalus or atrophy? A new approach for diagnosis using CSF dynamics. J Neurosurg 1996;85:1026-1035.

36. Kan P, Amini A, Hansen K, et al. Outcomes after decompressive craniectomy for severe traumatic brain injury in children. J Neurosurg 2006;105:337-342.

37. Shi SS, Zhang GL, Zeng T, Lin YF. Posttraumatic hydrocephalus associated with decompressive cranial defect in severe brain-injured patients. Chin J Traumatol 2011;14:343-347.

38. Anile C, De Bonis P, Di Chirico A, Ficola A, Mangiola A, Petrella G. Cerebral blood flow autoregulation during intracranial hypertension: a simple, purely hydraulic mechanism? Childs Nerv Syst 2009;25:325-335.

39. Takeuchi S, Nawashiro H, Wada K, et al. Ventriculomegaly after decompressive craniectomy with hematoma evacuation for large hemispheric hypertensive intracerebral hemorrhage. Clin Neurol Neurosurg 2013;115:317-322.

40. Mehta V, Holness RO, Connolly K, Walling S, Hall R. Acute hydrocephalus following aneurysmal subarachnoid hemorrhage. Can J Neurol Sci 1996;23:40-45.

41. Yoshioka H, Inagawa T, Tokuda Y, Inokuchi F. Chronic hydrocephalus in elderly patients following surbarachnoid hemorrhage. Surg Neurol 2000;53:119-125.

42. Poca MA, Sahuquillo J, Mataro M, Benejam B, Arikan F, Baguena M. Ventricular enlargement after moderate or severe head injury: a frequent and neglected problem. J Neurotrauma 2005;22:1303-1310. 